\title{
A pilot study: portable out-of-center sleep testing as an early sleep apnea screening tool in acute ischemic stroke
}

This article was published in the following Dove Press journal:

Nature and Science of Sleep

20 October 2015

Number of times this article has been viewed

\author{
Oleg Y Chernyshev' \\ David E McCarty' \\ Douglas E Moul ${ }^{2}$ \\ Cesar Liendo' \\ Gloria C Caldito' \\ Sai K Munjampalli' \\ Roger E Kelley ${ }^{3}$ \\ Andrew L Chesson Jr'
}

'Division of Sleep Medicine, Department of Neurology, Louisiana State University Health Sciences Center at Shreveport, LA ${ }^{2}$ Sleep Disorders Center, Cleveland Clinic, Cleveland, $\mathrm{OH},{ }^{3}$ Department of Neurology, Tulane University, New Orleans, LA, USA
Correspondence: Oleg Y Chernyshev Division of Sleep Medicine, Department of Neurology, Louisiana State University Health Sciences Center at Shreveport (LSU Health Shreveport), I50I Kings Highway, Shreveport, LA 7II30, USA

$\mathrm{Tel}+\mathrm{I} 3186757760$

Fax + I 3186757805

Email ochernyshevmd@yahoo.com
Introduction: Prompt diagnosis of obstructive sleep apnea (OSA) after acute ischemic stroke (AIS) is critical for optimal clinical outcomes, but in-laboratory conventional polysomnograms (PSG) are not routinely practical. Though portable out-of-center type III cardiopulmonary sleep studies (out-of-center cardiopulmonary sleep testing [OCST]) are widely available, these studies have not been validated in patients who have recently suffered from AIS. We hypothesized that OCST in patients with AIS would yield similar results when compared to conventional PSG.

Methods: Patients with AIS had simultaneous type III OCST and PSG studies performed within 72 hours from symptom onset. The accuracy of OCST was compared to PSG using: chi-square tests, receiver operatory characteristic curves, Bland-Altman plot, paired Student's $t$-test/Wilcoxon signed-rank test, and calculation of sensitivity, specificity, positive predictive value (PPV), and negative predictive value (NPV).

Results: Twenty-one out of 23 subjects with AIS (age $61 \pm 9.4$ years; $52 \%$ male; $58 \%$ AfricanAmerican) successfully completed both studies ( $9 \%$ technical failure). Nearly all (95\%) had Mallampati IV posterior oropharynx; the mean neck circumference was $16.8 \pm 1.6$ in. and the mean body mass index (BMI) was $30 \pm 7 \mathrm{~kg} / \mathrm{m}^{2}$. The apnea hypopnea index (AHI) provided by OCST was similar to that provided by PSG ( $19.8 \pm 18.0$ vs $22.0 \pm 22.7$, respectively; $P=0.49)$. On identifying subjects by OCST with an AHI $\geq 5$ on PSG, OCST had the following parameters: sensitivity $100 \%$, specificity $85.7 \%$, PPV 93\%, and NPV 100\%. On identifying subjects with an AHI $\geq 15$ on PSG, OCST parameters were as follows: sensitivity $100 \%$, specificity $83.3 \%$, PPV $81.8 \%$, and NPV 100\%. Bland-Altman plotting showed an overall diagnostic agreement between OCST and PSG modalities for an AHI cutoff $>5$, despite fine-grained differences in estimated AHIs.

Conclusion: Compared with PSG, OCST provides similar diagnostic information when run simultaneously in AIS patients. OCST is a reliable screening tool for early diagnosis of OSA in AIS patients.

Keywords: portable clinical screening, obstructive sleep apnea diagnosis, acute ischemic stroke, sleep testing in stroke, acute sleep medicine

\section{Introduction}

Stroke is the fifth leading cause of death in the US and the leading cause of disability, responsible for $\$ 20$ billion per year in lost wages. ${ }^{1}$

The most effective approach to diminish stroke-related burden is to reduce the incidence of first-time and recurrent stroke. Thus, recognition and treatment of modifiable risk factors are of particular importance. Besides the well-established modifiable risk factors, such as heart disease,${ }^{2}$ hypertension, ${ }^{3}$ diabetes mellitus (DM) ${ }^{4}$ smoking, ${ }^{5}$ 
obesity, ${ }^{6}$ and hypercholesterolemia, ${ }^{7}$ obstructive sleep apnea (OSA) is emerging as an important independent risk factor. ${ }^{8-10}$

OSA is very common in patients suffering from acute ischemic stroke (AIS), ranging from $45 \%$ to $95 \%$ of poststroke patients. ${ }^{11-15}$ In the acute stroke setting, the presence of OSA is associated with early neurological deterioration, increased stroke recurrence, increased mortality, increased length of hospital stay, and decreased functional recovery. ${ }^{12,14,16-22}$ OSA contributes to hypertension, myocardial infarction (MI), heart failure, and arrhythmias, all of which could also act as intermediate variables influencing the risk for stroke ${ }^{23-25}$ or its prognosis.

Continuous positive airway pressure (CPAP) therapy is an effective treatment of OSA. ${ }^{26}$ CPAP treatment of mildto-moderate OSA has been shown to reduce cardiovascular risk and improve systemic hypertension, significant factors for the development of ischemic stroke. ${ }^{27,28}$ In patients with ischemic stroke and OSA, positive pressure therapy of sleep apnea (SA) prevents new vascular events after ischemic stroke and reduces 5-year mortality. ${ }^{20,29,30}$

Given these facts, assertive and rapid initiation of CPAP in patients who have both AIS and OSA is essential - early initiation of OSA treatment in the acute poststroke setting could potentially minimize further damage to injured neural tissue and improve outcome. ${ }^{31}$ That said, no data are available on the optimal timing of diagnostic sleep studies and CPAP therapy in the acute setting, after stroke or transient ischemic attack (TIA).

Recently, several out-of-center sleep testing (OCST) devices were developed and validated for portable diagnosis of OSA in the ambulatory setting. ${ }^{32-36}$ OCST devices have been used to diagnose OSA in patients with congestive heart failure (CHF), ${ }^{37,38}$ hypertension, ${ }^{39}$ and stroke. ${ }^{40,41}$ The use of OCST devices for diagnosis of OSA may reduce costs by as much as $42 \%$, when compared with conventional polysomnography (PSG). ${ }^{42}$ Optimal validation studies comparing two techniques (such as OCST and PSG) involve simultaneous testing of both devices on the same subject, to eliminate confounding due to night-to-night variability of severity of disease. ${ }^{32}$ Few data exist comparing OCST devices to PSG using this simultaneous data acquisition method. ${ }^{40,42-44}$ Of importance, there are, to date, no published data reporting the synchronous comparison of OCST to PSG in the setting of stroke, whether acute, subacute, or chronic.

Our objective was to validate a portable, in-hospital OCST device for the diagnosis of OSA in patients with AIS (defined as $<72$ hours from stroke symptom onset) using simultaneously acquired PSG as the gold standard.

\section{Methods}

This pilot prospective study was initiated and conducted in the Louisiana State University Health Sciences Center, after an approval from a local institutional review board. Patients with AIS were recruited from LSU Health Sciences Center at Shreveport, LA, USA.

\section{Subjects}

Consecutive adults ( $>18$ years old) presenting to an academic medical center with AIS (defined as stroke symptom onset no greater than 72 hours) were recruited to participate. For women of child-bearing potential, a negative serum or urine pregnancy test was required. Other inclusion criteria included National Institute of Health Stroke Scale (NIHSS) score $\geq 1$ and modified Rankin Scale score $\geq 1$. All subjects completed informed consent procedures. For subjects who were unable to effectively communicate, informed consent was granted by the next of kin or legal caregiver.

Exclusion criteria included 1) refusal to sign the informed consent; 2) time from symptom onset to emergency department arrival $>72$ hours; 3 ) intracranial hemorrhage; 4) prestroke modified Rankin Scale score of 4 or greater; $5)$ respiratory distress requiring mechanical ventilation or supplemental oxygen; 6) cardiac or respiratory arrest within the past 3 months; 7) MI within the past 3 months; 8) any other unstable medical condition felt likely to interfere with participation; 9) life expectancy less than 6 months; and 10) prior known diagnosis of OSA and active pregnancy.

\section{Medical and neurological baseline evaluation}

Following informed consent, eligible subjects underwent a baseline medical assessment, which included a structured interview, standardized physical exam, and medical records review. Characteristics of the study population are provided in Table $1 .^{45}$

Neuroanatomic localization and etiology of AIS were determined using available radiographic imaging studies and the clinical presentation, based on described clinical subtypes and by using the TOAST classification system. ${ }^{46}$

Stroke symptom severity was prospectively measured using the baseline NIHSS. ${ }^{47}$ Functional level was determined using the modified Rankin Scale and the Barthel Index. ${ }^{48,49}$ The NIHSS assesses eleven domains of neurological function where a score of 0 indicates normal functioning and 
higher scores indicate worse stroke severity. The functional level was measured by 1) modified Rankin Scale, which has seven functional levels (a score of 0 indicates normal functioning and the highest score of 6 indicates death) and 2) Barthel Index, which is measured from 0 (complete disability) to 100 (normal function).

\section{PSG studies}

Standard-montage digitally acquired PSG (Alice 5 system, Respironics, Philadelphia, PA, USA) included nasal-oral pressure transducer and nasal-oral thermistor airflow tracing, abdominal and thoracic respiratory impedance plethysmography effort belts, digitally acquired pulse oximetry, electrocardiogram, frontal, central and occipital electroencephalogram, electrooculogram, position sensor, continuous video monitoring, chin electromyogram (EMG), and bilateral lower extremity EMG. Simultaneous acquisition of OCST, using Embletta X100, was also performed, with position sensor, pulse oximetry, nasal-oral pressure transducer, airflow traces, wrist actigraphy, and thoracic and abdominal strain-gauge effort sensors. According to the SCOPER classification, Embletta X100 device is identified as S-0, C-3, O-1, P-2, E-1, and R-2..$^{50}$

\section{Diagnosis of sleep apnea}

Studies were scored for sleep stages (PSG) and respiratory events (PSG and OCST) by an experienced scoring technician, according to the 2007 AASM Manual for the Scoring of Sleep and Associated Events. All scoring was independently reviewed by two board-certified sleep medicine physicians, who were blinded to the subject's clinical history and to the scoring of the simultaneous study (PSG vs OCST). Hypopnea rule $4 \mathrm{~A}$ (requiring $4 \%$ oxygen desaturation with a $30 \%$ reduction in airflow) was used. The apnea hypopnea index for the standard PSG (PSG-AHI) was calculated by dividing the total number of apneas and hypopneas by the total sleep time, in hours. ${ }^{51,52}$

The apnea hypopnea index for OCST (OCST-AHI) was calculated by dividing the total numbers of apneas and hypopneas by the total sleep time, as calculated by the actigraphy recording. The baseline oxygenation was defined as the oxygen saturation in the first minute of the study. The lowest oxygen desaturation level was defined as a lowest point of oxygen saturation detected in association with respiratory events during total sleep time.

The severity level of OSA was determined by the apnea hypopnea index (AHI), with mild OSA indicating AHI $>5$ and $<15$ per hour, moderate OSA indicating AHI $>15$ and
$<30$ per hour, and severe OSA indicating an $\mathrm{AHI} \geq 30$ per hour.

SA diagnosis (OSA or central sleep apnea [CSA]) was established based on The International Classification of Sleep Disorders, Second Edition (ICSD-2) and AASM criteria. ${ }^{51-53}$ SA was defined as OSA when $>50 \%$ of obstructive respiratory events were detected or was defined as CSA when $>50 \%$ of central respiratory events were detected.

Each study was performed for at least 6 hours of nocturnal sleep and was terminated after 12 hours of recording or upon the patient's request. PSG studies were acquired by a trained staff member at the patient's bedside. The patients were not transported out of their unit (ie, no change in the level of care). Usual nursing and physiotherapy practices were not altered during the study, and the patient was positioned according to the usual ward protocol.

\section{Analysis \\ Scoring}

An experienced technician, blinded to clinical history and concurrent study, performed the initial scoring analyses of all evaluations. Two board-certified sleep medicine physicians, similarly blinded, performed the final analyses of all evaluations and determined the presence and severity of SA.

\section{Statistical analysis}

Validity/accuracy: We sought to determine the validity of OCST to detect OSA of various severity levels (mild, moderate, and severe, as defined earlier), using traditional PSG as ground truth. Sensitivity, specificity, positive predictive value (PPV), negative predictive value (NPV), and their corresponding 95\% confidence intervals (obtained with the binomial distribution) were calculated, and receiver operating characteristic (ROC) curves were constructed for each severity level. We planned to accept the validity of OCST for detecting and determining the severity of OSA if the area under the ROC (AUROC) for each severity level was 0.9 or higher. To determine the accuracy of OCST, OCST-AHIs were compared to PSG-AHIs using the Wilcoxon signedrank test, and a Bland-Altman curve was constructed. We planned to accept the accuracy of OCST if the simultaneously obtained OCST- and PSG-AHIs were statistically regarded as similar $(P>0.05)$.

Descriptive statistics: Baseline characteristics and outcomes were described using standard statistical parameters (means with standard deviations, medians, and proportions). Several variables were analyzed, including stroke characteristics, patient demographic data, and sleep study 
Table I Clinical characteristics and outcomes of the study population with comparisons between SA (OSA + CSA) and non-SA stroke subjects

\begin{tabular}{|c|c|c|c|}
\hline Characteristic/outcome & SA subjects $(N=14)$ & Non-SA subjects $(\mathrm{N}=7)$ & $P$-value \\
\hline Age (years) & $60.6 \pm I I .9,60.0,42-8 \mid$ & $60.9 \pm 3.5,62.0,56-65$ & 0.93 \\
\hline Male sex & $8(57.1)$ & $3(42.9)$ & 0.66 \\
\hline Race & & & 1.0 \\
\hline White & $6(42.9)$ & $3(42.9)$ & \\
\hline African-American & $8(57.1)$ & $4(57.1)$ & \\
\hline Epworth Sleepiness Scale & $15.9 \pm 3.3,16.0,10-24$ & $13.3 \pm 4.6,12.0,10-18$ & 0.14 \\
\hline Neck circumference (inches) & $17.4 \pm 1.5,17.5,15.5-20.0$ & $15.6 \pm 1.2,15.5,13.5-17.5$ & $0.02^{*}$ \\
\hline Mallampati Score & & & $>0.99$ \\
\hline 3 & I (7.I) & $0(0.0)$ & \\
\hline 4 & $13(92.9)$ & $7(100)$ & \\
\hline BMI $\left(\mathrm{kg} / \mathrm{m}^{2}\right)$ & $33.1 \pm 6.0,33.4,21.4-44.9$ & $23.8 \pm 2.6,25.5,19.1-25.8$ & $<0.0 \mathrm{I}^{* *}$ \\
\hline \multicolumn{4}{|l|}{ Risk factors } \\
\hline Obesity & II (78.6) & $0(0)$ & $<0.0 \mathrm{I}^{* *}$ \\
\hline Previous OSA Dx & $0(0)$ & $0(0)$ & NA \\
\hline Current OSA treatment & $0(0)$ & $0(0)$ & NA \\
\hline HTN & II (78.6) & $7(100.0)$ & 0.52 \\
\hline DM & $8(57.1)$ & I (I4.3) & 0.16 \\
\hline DM neuropathy & I (7.I) & $0(0)$ & $>0.99$ \\
\hline HLP & $12(85.7)$ & $3(42.9)$ & 0.12 \\
\hline Hypothyroidism & I (7.I) & $0(0)$ & $>0.99$ \\
\hline Atrial fibrillation & I (7.I) & $0(0)$ & $>0.99$ \\
\hline CAD & $3(2 I .4)$ & I (I4.3) & $>0.99$ \\
\hline Previous stroke & $2(14.3)$ & I (I4.3) & 1.0 \\
\hline MI & $0(0)$ & $0(0)$ & NA \\
\hline Previous MI & $3(2 \mid .4)$ & I (I4.3) & $>0.99$ \\
\hline $\mathrm{H} \times \mathrm{CABG}$ & I (7.I) & I (I4.3) & $>0.99$ \\
\hline Hx carotid stenosis & $0(0)$ & I (I4.3) & 0.33 \\
\hline PVD & $\mathrm{I}(7.1)$ & I (I4.3) & $>0.99$ \\
\hline Gout & I (7.I) & $0(0)$ & $>0.99$ \\
\hline Smoking tobacco & $6(42.9)$ & $6(85.7)$ & 0.16 \\
\hline Smoking packs per day & $0.4 \pm 0.6,0,0-2$ & $0.7 \pm 0.5,0.5,0-1.5$ & 0.16 \\
\hline Years of tobacco smoking & $10.7 \pm 14.8,0,0-40$ & $19.3 \pm 11.0,20,0-30$ & 0.17 \\
\hline Alcohol use & I (7.I) & $3(42.9)$ & $0.09 * * *$ \\
\hline Alcohol drinks per day & $0.1 \pm 0.5,0,0-2$ & $0.6 \pm 0.8,0,0-2$ & $0.07 * * *$ \\
\hline Years of alcohol use & $0.4 \pm 1.3,0,0-5$ & $4.9 \pm 7.6,0,0-20$ & $0.05 * * *$ \\
\hline Stroke vascular territory location & & & 0.68 \\
\hline R MCA & $5(35.7)$ & $2(28.6)$ & \\
\hline L MCA & $4(28.6)$ & $3(42.9)$ & \\
\hline L ACA & I (7.I) & $0(0.0)$ & \\
\hline R PCA & $0(0.0)$ & $2(28.6)$ & \\
\hline L PCA & $\mathrm{I}(7.1)$ & $0(0.0)$ & \\
\hline $\mathrm{R} M C A+P C A$ & $\mathrm{I}(7.1)$ & $0(0.0)$ & \\
\hline $\mathrm{LMCA}+\mathrm{ACA}$ & I (7.I) & $0(0.0)$ & \\
\hline Basilar artery & I (7.I) & $0(0.0)$ & \\
\hline \multicolumn{4}{|l|}{ TOAST classification } \\
\hline Large vessel & $4(28.6)$ & $4(57.1)$ & 0.35 \\
\hline Cardioembolism & $2(14.3)$ & $0(0)$ & 0.53 \\
\hline Small vessel & $3(21.4)$ & $3(42.9)$ & 0.35 \\
\hline Other/rare causes & $0(0)$ & $0(0)$ & NA \\
\hline Undetermined/no cause & $5(35.7)$ & $0(0)$ & 0.12 \\
\hline Etiology of cardio embolism & & & 0.68 \\
\hline None & $12(85.8)$ & $7(100.0)$ & \\
\hline Aortic valve replacement & I (7.I) & $0(0.0)$ & \\
\hline Atrial fibrillation & $\mathrm{I}(7.1)$ & $0(0.0)$ & \\
\hline
\end{tabular}


Table I(Continued)

\begin{tabular}{|c|c|c|c|}
\hline Characteristic/outcome & SA subjects $(N=14)$ & Non-SA subjects $(\mathrm{N}=7)$ & $P$-value \\
\hline Neurological complications & & & $>0.99$ \\
\hline Seizure disorder & I (7.I) & $0(0.0)$ & \\
\hline Cerebral edema & $2(14.3)$ & I (I4.3) & 1.0 \\
\hline Hemorrhagic transformation & $2(14.3)$ & $0(0.0)$ & 0.53 \\
\hline Type of $\mathrm{HT}$ & & & 0.52 \\
\hline Absent & $12(85.7)$ & $7(100.0)$ & \\
\hline Type I & $2(14.3)$ & $0(0.0)$ & \\
\hline Medical complications & & & $>0.99$ \\
\hline None & $12(85.8)$ & $7(100.00)$ & \\
\hline Urinary tract infection & I (7.I) & $0(0.0)$ & \\
\hline $\mathrm{Ml}$ and death & $\mathrm{I}(7.1)$ & $0(0.0)$ & \\
\hline Neurological scales & & & 0.52 \\
\hline NIHSS at Visit I & $5.8 \pm 3.5,5.0,2-13$ & $7.6 \pm 5.7,5.0,2-19$ & \\
\hline NIHSS at Visit 2 & $1.4 \pm 1.8,1.0,0-5.0$ & $3.5 \pm 4.8,1.5,0-13$ & 0.32 \\
\hline \# Missing & 4 & 1 & \\
\hline mRS at Visit I & $3.1 \pm 1.3,3.0,1-5$ & $3.1 \pm 1.3,3.0,1-5$ & 0.88 \\
\hline mRS at Visit I & & & $>0.99$ \\
\hline Mild $(0-I)$ & $2(14.3)$ & I (I4.3) & \\
\hline Moderate (2-3) & $7(50.0)$ & $3(42.9)$ & \\
\hline Severe (4-5) & $5(35.7)$ & $3(42.9)$ & \\
\hline mRS at Visit 2 & $1.7 \pm 1.8,1.0,0-6$ & $1.5 \pm 1.4,1.0,0-4$ & 0.92 \\
\hline \# Missing & 3 & 1 & \\
\hline mRS at Visit 2 & & & 0.44 \\
\hline Mild $(0-I)$ & $6(54.6)$ & $4(66.7)$ & \\
\hline Moderate (2-3) & $4(36.4)$ & I (I6.7) & \\
\hline Severe $(4-5)$ & $0(0.0)$ & I (I6.7) & \\
\hline Death (6) & I (9.1) & $0(0.0)$ & \\
\hline \# Missing & 3 & I & \\
\hline Barthel Index at Visit I & $57.1 \pm 25.0,52.5,20-100$ & $51.4 \pm 27.8,45.0,20-90$ & 0.83 \\
\hline Barthel Index at Visit I & & & 0.83 \\
\hline$\leq 30$ & $2(14.3)$ & $2(28.6)$ & \\
\hline $31-60$ & $6(42.9)$ & $3(42.9)$ & \\
\hline $6 I-100$ & $6(42.9)$ & $2(28.6)$ & \\
\hline Barthel Index at Visit 2 & $92.5 \pm I I .1,100,75-100$ & $86.7 \pm 21.1,95,45-100$ & 0.49 \\
\hline \# Missing & 4 & I & \\
\hline Barthel Index at Visit 2 & & & 0.38 \\
\hline$\leq 30$ & $0(0.0)$ & $0(0.0)$ & \\
\hline $31-60$ & $0(0.0)$ & $I(16.7)$ & \\
\hline $61-100$ & $10(100.0)$ & $5(83.1)$ & \\
\hline \# Missing & 4 & 1 & \\
\hline \multicolumn{4}{|l|}{ Review of systems } \\
\hline Fatigue & $12(85.7)$ & $6(85.7)$ & 1.0 \\
\hline Daytime sleepiness & II (78.6) & $6(85.7)$ & $>0.99$ \\
\hline Poor concentration & $13(92.9)$ & $6(85.7)$ & $>0.99$ \\
\hline Poor memory & $6(42.9)$ & $2(28.6)$ & 0.66 \\
\hline Depression & I (7.I) & $2(28.6)$ & 0.25 \\
\hline
\end{tabular}

Notes: Values are given as number $(\%)$ or mean \pm SD, median, range. "Significant at $5 \%$ level $(0.01<P<0.05)$; ${ }^{* *}$ significant at $1 \%$ level $(P<0.01)$; ${ }^{* * *}$ not significant at $5 \%$ level but significant at $10 \%$ level $(0.05<P<0.10)$. No cocaine use, amphetamine use, and marijuana use were reported by the patients in both groups.

Abbreviations: SA, sleep apnea; OSA, obstructive sleep apnea; CSA, central sleep apnea; mean, mean value; SD, standard deviation; BMI, body mass index; Dx, diagnosis; NA, no applicable statistical test; HTN, hypertension; DM, diabetes mellitus; HLP, hyperlipidemia; CAD, coronary artery disease; MI, myocardial infarction; Hx, history of; CABG, coronary artery bypass grafting; PVD, peripheral vascular disease; R, the right side; MCA, middle cerebral artery; L, the left side; ACA, anterior cerebral artery; PCA, posterior cerebral artery; HT, hemorrhagic transformation; NIHSS, National Institute of Health Stroke Scale; Visit I, the evaluation during hospital admission; Visit 2, the evaluation at 90 days from the hospital discharge; mRS, modified Rankin Scale. Barthel Index. 
variables. Prevalence of SA (obstructive, central) was estimated.

SA and non-SA stroke patients were compared using the chi-square tests (or Fisher's exact tests, as appropriate) for categorical variables and the two-sample Student's $t$-tests (or Wilcoxon rank-sum tests, as appropriate) for continuousmodeled variables. A $P$-value $<0.05$ was used to determine statistical significance.

\section{Results}

Between October 1, 2010 and September 30, 2011, 126 patients with stroke-like symptoms were admitted to the neurology inpatient service at LSU Health Sciences Center at Shreveport. Of these, 25 subjects met all inclusion criteria, with four subjects later being excluded for various reasons. Paired studies from 21 subjects were available for final analysis (Figure 1).

\section{Patient characteristics and SA prevalence}

Demographic and clinical characteristics of the study population are included in Table 1 . Twenty one out of 23 AIS patients (age $61 \pm 9.4$ years; $52 \%$ male; 58\% African-American) successfully completed both of the simultaneous screenings $(9 \%$ technical failure). All subjects did not have previously established SA diagnosis and treatment. The median time from the onset of stroke symptoms to sleep study was 2 days.

There was evidence of SA in 14/21 (67\%) subjects. OSA was present in 10/21 (48\%) subjects, and CSA in 4/21 (19\%) subjects. Seven of 21 (33\%) subjects with AIS did not have evidence of sleep disordered breathing. Subjects with SA had higher body mass index (BMI) and were more likely to be classified as obese and to have larger neck circumference, compared to subjects without SA, but otherwise, clinical and physical examination characteristics were similar (Table 1). Clinical stroke types, complications, and measured outcomes did not differ in SA subjects compared to those without SA.

\section{Accuracy and validity of OCST compared with PSG ("Gold standard")}

Accuracy and validity of OCST for diagnosis of SA (OSA and CSA)

Paired $t$-test (if differences between OCST and PSG were normally distributed) or the Wilcoxon signed-rank test (if the differences were non-normal) was used to compare OCST and PSG values on AHI, central apnea index (CA index), obstructive apnea index (OA index), mixed apnea index (MA index), hypopnea index, and oxygen desaturation index. Compared with PSG as ground truth, OCST provided accurate information for detection of SA. There were no significant differences in the variables of AHI (median: 23.8 vs 34.8 events per hour), CA index (median: 4.8 vs 3.3 events per hour), OA index (median: 10.4 vs 5.5 events per hour), MA index (median: 0.1 vs 0 events per hour), hypopnea index (median: 3.2 vs 3.1 events per hour), and $4 \%$ oxygen desaturation index (median: 22.8 vs 16.7 events per hour) (Table 2).

When used to estimate SA severity (mild, moderate, and severe, as defined earlier), OCST demonstrated sensitivity: $100 \%, 100 \%$, and $62.5 \%$, respectively; specificity: $85.7 \%$,

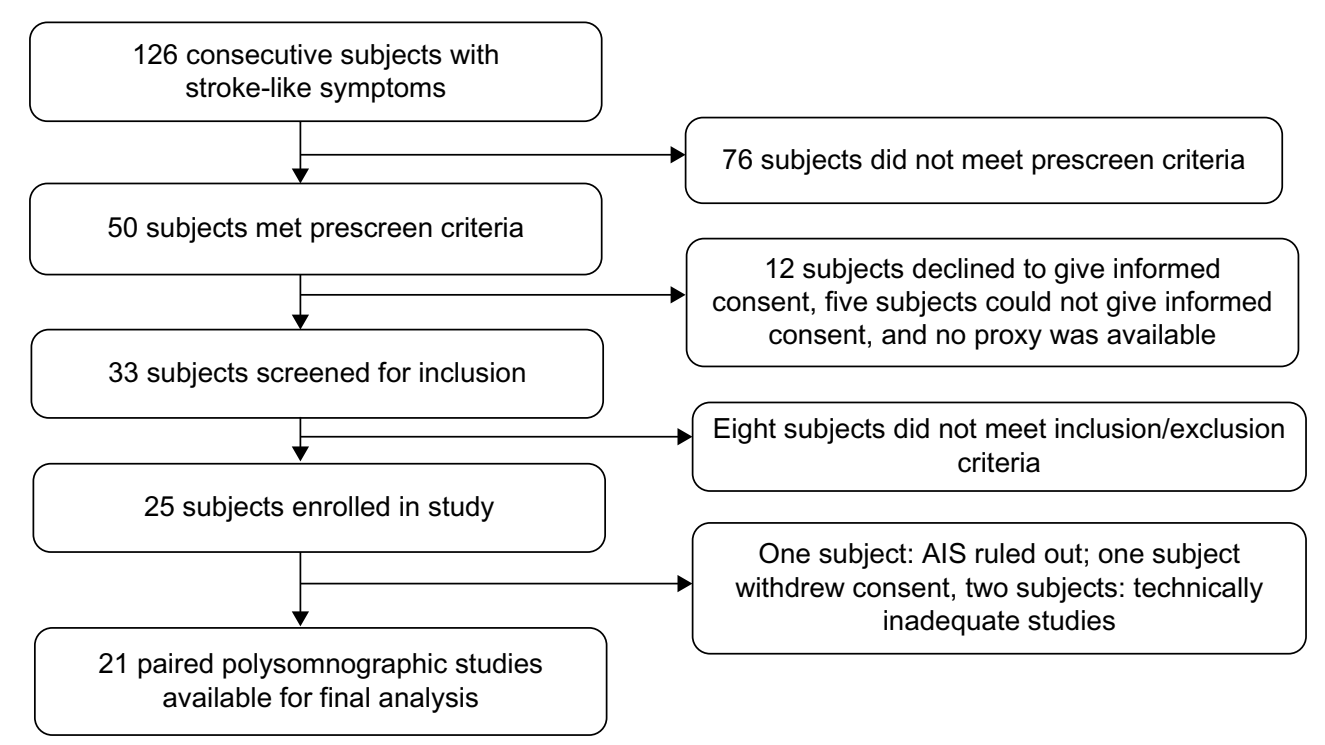

Figure I Subject enrollment flow. 
Table 2 Comparison between portable out-of-center sleep testing and PSG in acute ischemic stroke among patients with SA and among those with OSA $(n=14)$

\begin{tabular}{|c|c|c|c|}
\hline Characteristics & $\begin{array}{l}\text { OCST, mean } \pm S D \text {, } \\
\text { median, range }\end{array}$ & $\begin{array}{l}\text { PSG, mean } \pm \text { SD, } \\
\text { median, range }\end{array}$ & $P$-value \\
\hline \multicolumn{4}{|l|}{ Among SA patients $(n=14)$} \\
\hline \multicolumn{4}{|l|}{ Events/hour } \\
\hline $\mathrm{AHI}$ & $28.6 \pm 15.9,23.8,7.2-55.2$ & $32.6 \pm 20.9,34.8,6-61.9$ & 0.99 \\
\hline CA index & $9.1 \pm 10.2,4.8,0-35.1$ & $|3.5 \pm| 8.4,3.3,0-56 . \mid$ & 0.99 \\
\hline OA index & $14.5 \pm 11.9,10.4,1.1-37.5$ & $12.6 \pm \mid 7.2,5.5,0-54.5$ & 0.15 \\
\hline MA index & $1.1 \pm 2.7,0.1,0-10.2$ & $1.8 \pm 4.1,0,0-15.4$ & 0.96 \\
\hline Hypopnea index & $3.9 \pm 3.8,3.2,0-13.3$ & $4.6 \pm 5.6,3.1,0-20.2$ & 0.40 \\
\hline Desaturation index (4\%) & $23.8 \pm 17.5,22.8, \mid .4-58.4$ & $22.4 \pm 20.5,16.7,0-72.4$ & 0.53 \\
\hline \multicolumn{4}{|c|}{ Among OSA patients $(n=10)$} \\
\hline \multicolumn{4}{|c|}{ Events/hour } \\
\hline $\mathrm{AHI}$ & $29.1 \pm 16.8,23.8,7.2-55.2$ & $27.6 \pm 20.2,23.6,6-55.2$ & 0.08 \\
\hline CA index & $4.7 \pm 6.4,2.2,0-16.4$ & $4.2 \pm 8.3,0.6,0-26.6$ & 0.11 \\
\hline OA index & $18.0 \pm 12.4,15.1,1.5-37.5$ & $16.4 \pm 19,6.2,0.1-54.5$ & 0.32 \\
\hline MA index & $1.3 \pm 3.2,0.1,0-10.2$ & $0.5 \pm I .1,0,0-3.1$ & 0.28 \\
\hline Hypopnea index & $5.1 \pm 3.8,5.2,0-13.3$ & $6.4 \pm 5.8,5.4,0.6-20.2$ & 0.29 \\
\hline Desaturation index (4\%) & $28.2 \pm 17.9,28.4, \mid .7-58.4$ & $28.6 \pm 21.1,22.2,2.6-72.4$ & 0.87 \\
\hline
\end{tabular}

Abbreviations: SA, sleep apnea; OSA, obstructive sleep apnea; OCST, out-of-center sleep testing; mean, mean value; SD, standard deviation; PSG, polysomnography testing; $\mathrm{AHI}$, apnea hypopnea index; $\mathrm{CA}$ index, central apnea index; $\mathrm{OA}$ index, obstructive apnea index; MA index, mixed apnea index.

$83.3 \%$, and 100\%, respectively; PPV: $93.3 \%, 81.8 \%$, and $100 \%$, respectively; NPV: $100 \%, 100 \%$, and $81.2 \%$, respectively. Exact $95 \%$ confidence intervals for these proportions were obtained with binomial distribution (Table 3).

\section{Accuracy and validity of OCST for diagnosis of OSA}

When only patients with OSA were analyzed $(n=10)$, the accuracy of OCST for estimation of relevant parameters was also acceptable. Analysis did not demonstrate any significant difference in the variables of AHI (median: 23.8 vs 23.6 events per hour), CA index (median: 2.2 vs 0.6 events per hour), OA index (median: 15.1 vs 6.2 events per hour), MA index (median: 0.1 vs 0 events per hour), hypopnea index (median: 5.2 vs 5.4 events per hour), and $4 \%$ oxygen desaturation index (median: 28.4 vs 22.2 events per hour) (Table 2).

Again, using PSG as ground truth, the validity of OCST for the classification of mild, moderate, and severe SA was evaluated, with OCST demonstrating sensitivity: $100 \%, 100 \%$, and $75 \%$, respectively; specificity: $85.7 \%, 83.3 \%$, and $92.3 \%$, respectively; PPV: $90.9 \%, 71.4 \%$, and $75 \%$, respectively; NPV: $100 \%, 100 \%$, and $92.3 \%$, respectively. Exact $95 \%$ confidence limits were likewise obtained for these proportions with the binomial distribution (Table 3).

Accuracy and validity of OCST for diagnosis of CSA Except for determining severe SA using an AHI $>30$ for which sensitivity (33.3\%) and NPV (20\%) were low, the
Table 3 Sensitivity, specificity, PPV, and NPV of OCST for diagnosis of SA, OSA, and CSA using three AHI thresholds with PSG as gold standard

\begin{tabular}{|c|c|c|c|c|}
\hline Diagnosis & Accuracy & $\mathrm{AHI}>5$ & $A H I>I 5$ & $\mathrm{AHI}>\mathbf{3 0}$ \\
\hline \multirow{8}{*}{$\begin{array}{l}\text { SA (OSA + CSA) } \\
(n=2 I)\end{array}$} & Sensitivity & $100 \%$ & $100 \%$ & $62.5 \%$ \\
\hline & $95 \% \mathrm{Cl}$ & $81 \%-100 \%$ & $81 \%-100 \%$ & $41 \%-83 \%$ \\
\hline & Specificity & $85.7 \%$ & $83.3 \%$ & $100 \%$ \\
\hline & $95 \% \mathrm{Cl}$ & $62 \%-96 \%$ & $58 \%-94 \%$ & $81 \%-100 \%$ \\
\hline & PPV & $93.3 \%$ & $81.8 \%$ & $100 \%$ \\
\hline & $95 \% \mathrm{Cl}$ & $71 \%-97.5 \%$ & $57 \%-95 \%$ & $81 \%-100 \%$ \\
\hline & NPV & $100 \%$ & $100 \%$ & $81.2 \%$ \\
\hline & $95 \% \mathrm{Cl}$ & $81 \%-100 \%$ & $81 \%-100 \%$ & $56 \%-94 \%$ \\
\hline \multirow[t]{8}{*}{ OSA $(n=17)$} & Sensitivity & $100 \%$ & $100 \%$ & $75 \%$ \\
\hline & $95 \% \mathrm{Cl}$ & $79 \%-100 \%$ & $79 \%-100 \%$ & $47 \%-94 \%$ \\
\hline & Specificity & $85.7 \%$ & $83.3 \%$ & $92.3 \%$ \\
\hline & $95 \% \mathrm{Cl}$ & $59 \%-96 \%$ & $51 \%-94 \%$ & $66.5 \%-98.5 \%$ \\
\hline & PPV & $90.9 \%$ & $71.4 \%$ & $75 \%$ \\
\hline & $95 \% \mathrm{Cl}$ & $65 \%-99 \%$ & $43 \%-89 \%$ & $47 \%-94 \%$ \\
\hline & NPV & $100 \%$ & $100 \%$ & $92.3 \%$ \\
\hline & $95 \% \mathrm{Cl}$ & $79 \%-100 \%$ & $79 \%-100 \%$ & $66.5 \%-98.5 \%$ \\
\hline \multirow[t]{8}{*}{$\operatorname{CSA}(n=I I)$} & Sensitivity & $100 \%$ & $100 \%$ & $33.3 \%$ \\
\hline & $95 \% \mathrm{Cl}$ & $70 \%-100 \%$ & $70 \%-100 \%$ & $9 \%-66 \%$ \\
\hline & Specificity & $85.7 \%$ & $100 \%$ & $100 \%$ \\
\hline & $95 \% \mathrm{Cl}$ & $51.5 \%-98.5 \%$ & $70 \%-100 \%$ & $70 \%-100 \%$ \\
\hline & PPV & $80 \%$ & $100 \%$ & $100 \%$ \\
\hline & $95 \% \mathrm{Cl}$ & $46 \%-96 \%$ & $70 \%-100 \%$ & $70 \%-100 \%$ \\
\hline & NPV & $100 \%$ & $100 \%$ & $20 \%$ \\
\hline & $95 \% \mathrm{Cl}$ & $70 \%-100 \%$ & $70 \%-100 \%$ & $4 \%-54 \%$ \\
\hline
\end{tabular}

Abbreviations: PPV, positive predictive value; NPV, negative predictive value; OCST, out-of-center sleep testing; SA, sleep apnea; OSA, obstructive sleep apnea; CSA, central sleep apnea; AHI, apnea hypopnea index; PSG, polysomnography testing; $\mathrm{Cl}$, confidence interval. 
accuracy of OCST in subjects with CSA was acceptable for determining mild and moderate SA (Table 3).

OCST, compared with PSG, showed validity in the estimation of severity level (mild, moderate, and severe) with sensitivity: $100 \%, 100 \%$, and $33.3 \%$, respectively; specificity: $85.7 \%, 100 \%$, and 100\%, respectively; PPV: $80 \%, 100 \%$, and $100 \%$, respectively; NPV: $100 \%, 100 \%$, and $20 \%$, respectively.

\section{Validity and accuracy of OCST for the diagnosis of SA by ROC curves and Bland-Altman plot}

AUROC analysis revealed high correlation between the severity levels classified by OCST compared with PSG. The AUROC for detection of OSA was found to be 1.0 for mild, 0.95 for moderate, and 0.97 for severe (Figure 2).

Bland-Altman plot analysis indicates that though OCST tends to over- or underestimate the AHI, misclassification of disease presence and severity level is rare (Figure 3 ).

\section{Discussion}

Our study demonstrates the feasibility, accuracy, and validity of a portable, in-hospital cardiopulmonary screening modality (OCST) for the diagnosis of OSA and CSA, as compared to conventional PSG in patients with AIS.

Our findings are in concordance with other studies, demonstrating the validation of the portable technology in ambulatory and hospital settings. ${ }^{37-40}$ These studies led to the development of the guidelines for the use of portable technology. OCST may be considered as the "silver standard" of SA diagnosis in portable, out of sleep center conditions. $^{54-56}$

Although the AASM does not recommend using ambulatory OCST in complex patients with medical comorbidities (CHF, chronic obstructive pulmonary disease [COPD]), our analysis indicates that such testing is supported in settings when it is perhaps unsafe or impractical to perform standard in-laboratory PSG testing. The acute bedside evaluation in a high-risk hospitalized patient is an example of one of these settings. Practically, PSG is not always readily available to hospitalized patients with high risk of OSA (eg, patients with acute stroke or acute coronary syndromes). As a result, there is a need for reliable, portable, and inexpensive tools to establish the bedside diagnosis of OSA and accurately estimate its severity.
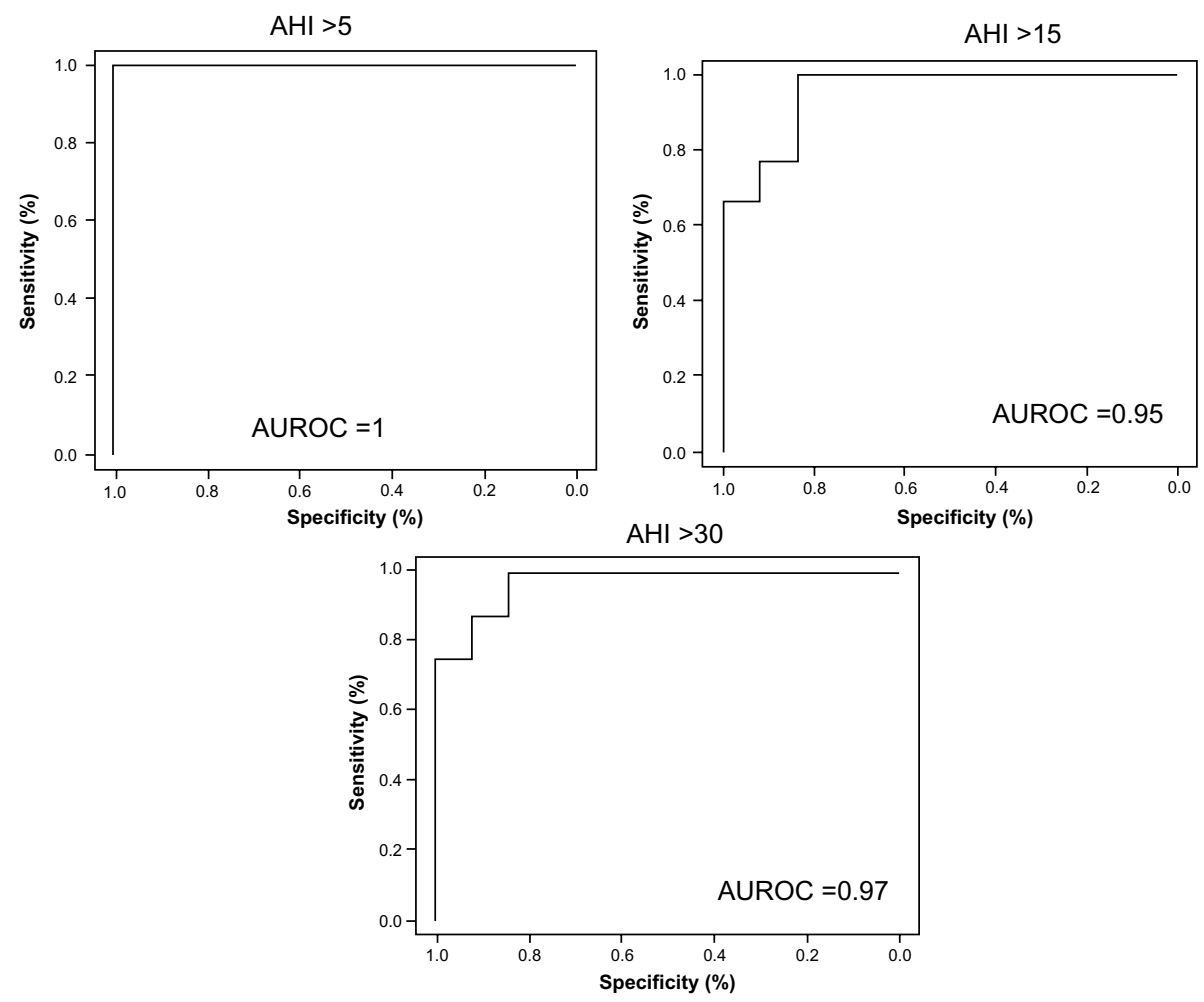

Figure 2 The validity of OCST for the diagnosis of SA by ROC curves and Bland-Altman plot.

Notes: There is an overall diagnostic agreement between OCST and PSG modalities for the AHI cutoffs $>5$ (AUROC =I), $>$ I5 (AUROC =0.95), $>30$ (AUROC =0.97),

Abbreviations: OCST, out-of-center sleep testing; SA, sleep apnea; ROC, receiver operating characteristic; PSG, polysomnography testing; AHI, apnea hypopnea index; AUROC, area under receiver operating characteristic curve. 


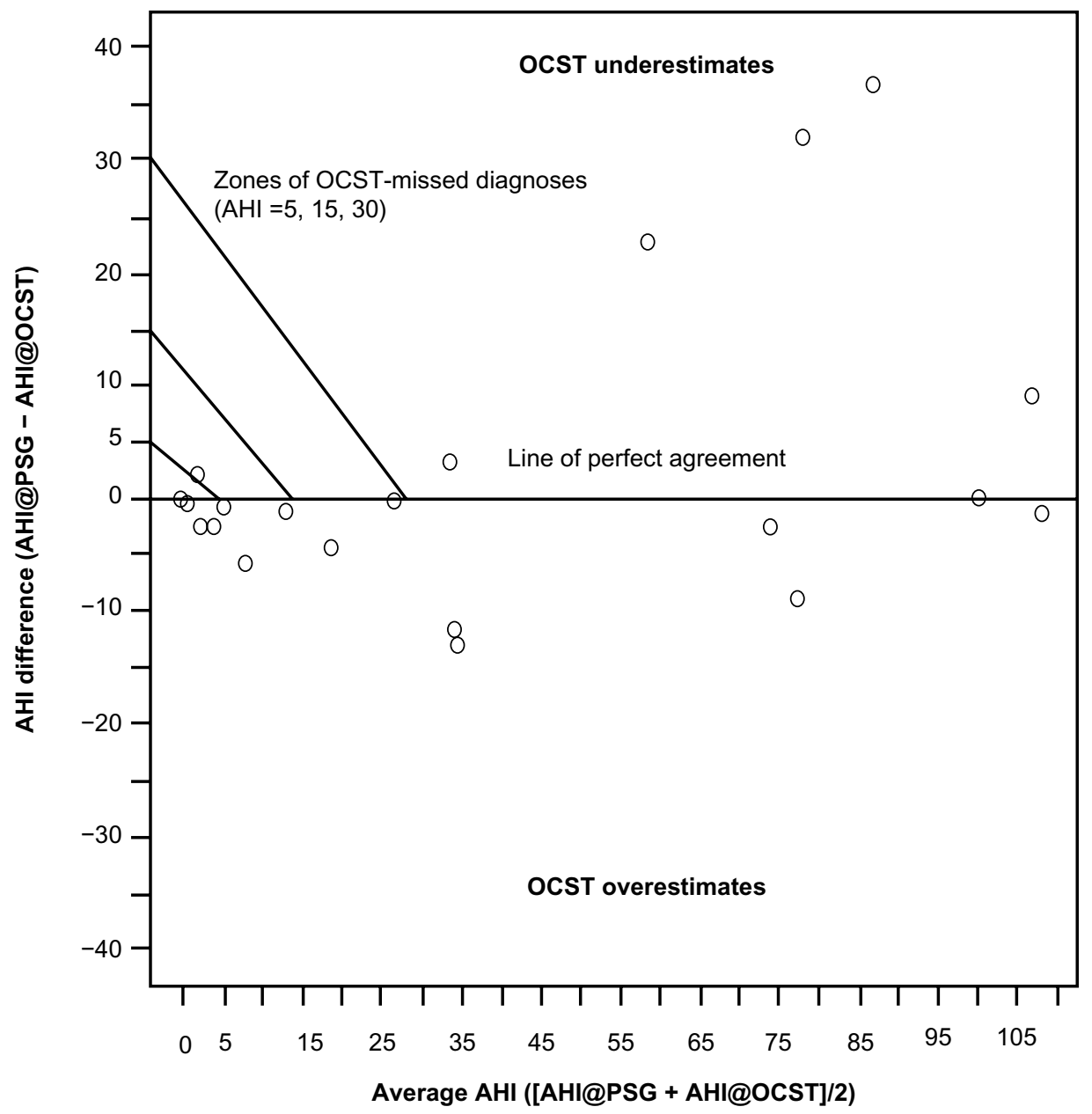

Figure 3 The Accuracy of OCST for the diagnosis of SA by Bland-Altman plot.

Notes: There is an overall diagnostic agreement between OCST and PSG modalities for an AHI cutoff $>5$, despite fine-grained differences in estimated AHIs. Abbreviations: OCST, out-of-center sleep testing; SA, sleep apnea; PSG, polysomnography testing; AHI, apnea hypopnea index.

The role of OCST in diagnosis of OSA is under constant discussion. ${ }^{56}$ The OCST is well recognized as a "diseasefinding" tool in OSA diagnosis. ${ }^{57}$ With appropriate clinical prescreening (eg, STOP BANG questionnaire), the portable OCST could be utilized as a screening or "disease-finding" tool to assist early delivery of positive airway pressure (PAP) therapy to acute stroke patients with OSA. ${ }^{58-66}$ A potentially practical approach to screening and testing for SA in the acute setting is presented in Figure 4. This approach, after appropriate validation by randomized controlled trials, can also be potentially applied in any acute hospital setting in patients with a high SA probability, which may create a new opportunity for the development of combined acute sleep medicine protocols, providing a new role for sleep medicine centers in bedside in-hospital diagnosis and treatment of SA. It also introduces a new role for sleep medicine centers to play and a new opportunity for the development of the acute sleep medicine field as a part of the integrated sleep medicine paradigm.

The chief limitation to our study is the small sample size, which may have concealed clinical differences between those with and without SA, or differences in clinical course and outcomes. In addition, although, no statistically significant differences in AHI estimation were detected between OCST and PSG in OSA subjects, the reported data $(P=0.08)$ may represent a statistical trend. This is likely due to the tendency of OCST to over- or underestimate the AHI. It is possible that a larger sample size would reveal more variability of AHI estimation comparing OCST to PSG, and that this could negatively impact the accuracy rating. Despite this, however, the ability of OCST to correctly classify disease severity was robust, suggesting that the clinical importance of this variability of AHI estimation is arguably limited. The limitations of our study are similar to other SA studies in stroke population..$^{40,41,67}$ 


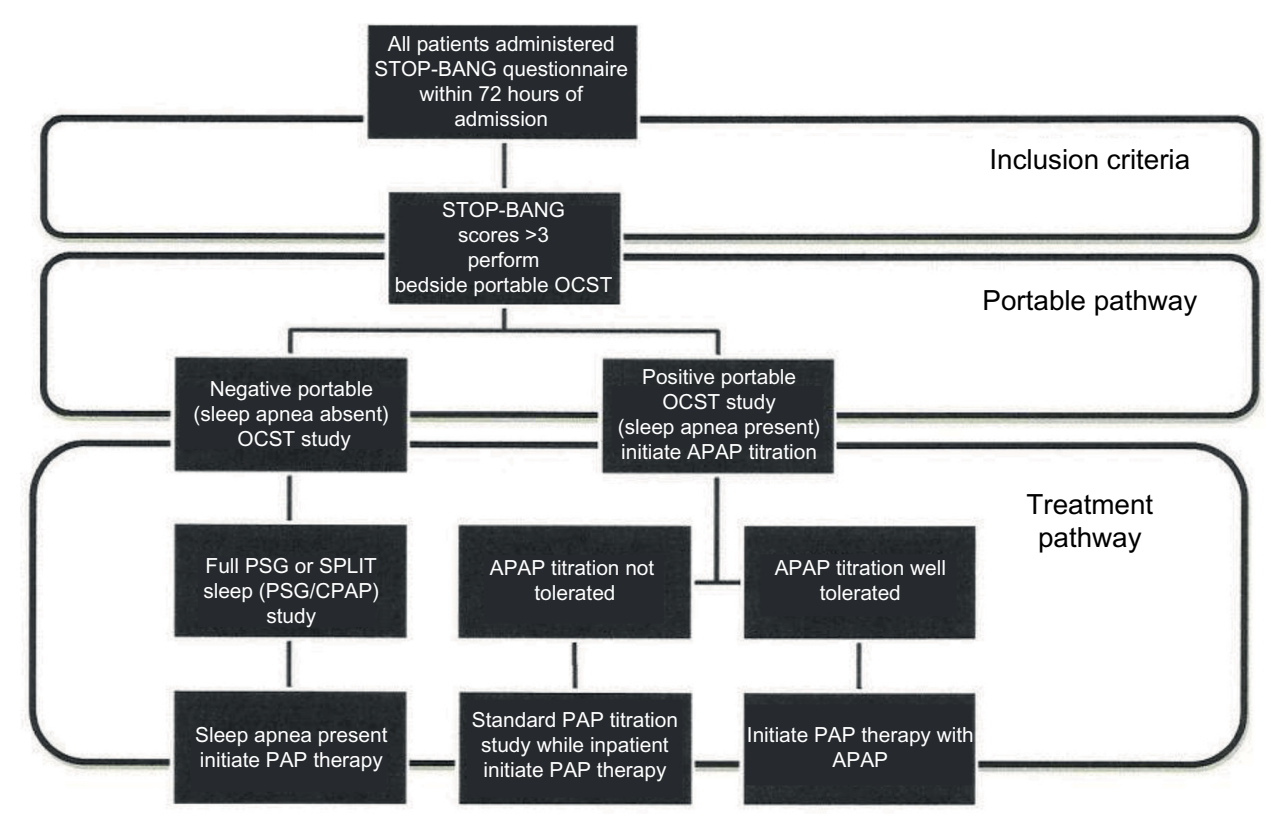

Figure 4 An example of acute sleep medicine ischemic stroke protocol within 72 hours from the onset of acute ischemic stroke. Follow-up sleep clinic visits every $3-6$ months with sleep breathing disorder questionnaires and studies repeated to assess clinical improvement status.

Abbreviations: APAP, automated positive airway pressure; PSG, polysomnography; CPAP, continuous positive airway pressure; PAP, positive airway pressure; OCST, out-of-center cardiopulmonary sleep testing.

Kepplinger et al have noted that "Early SA screening on a stroke unit is feasible in patients with acute cerebral ischemia". ${ }^{41}$ This is likely correct; however, evidence for the cross-reliability between a portable system and a formal PSG, as conducted on a hospital stroke unit itself, has been limited. The present study addresses the key question whether there is reliability between a portable system and an in-laboratory level of determination, in an acute poststroke inpatient setting. The feasibility of rapid diagnosis of OSA in stroke is an additionally important question that depends on finding reliability, but also would involve facility-level decision making about acquiring the equipment, personnel, and procedures needed to make such a treatment enhancement possible in a particular medical facility. However, the present study also separately addresses this feasibility question in a limited way, as the facility it was conducted in was relatively comparable to most other academic medical centers where stroke and sleep medicine care are jointly offered. The fact that AIS patients are brought to our institution for treatment and the availability of both portable OCST and in-laboratory conventional PSG in our stroke unit provide the main criteria for the feasibility of the present sleep study. Eligible subjects who gave informed consent provided the data for the screening of SA among them. Analysis of the data using appropriate statistical techniques made possible the testing of the study hypothesis that the portable OCST is a valid and accurate test for the diagnosis of SA among patients with AIS.
More studies should be performed to determine the safety and effects of acute CPAP treatment of OSA in stroke patients on stroke outcomes: functional recovery, morbidity, and 5-year mortality. These challenging studies cannot be done without the use of reliable portable diagnostic screening tools. The portable out-of-center sleep testing can be used to establish early and timely SA (OSA or CSA) diagnosis.

These projects and others may help generate the evidence needed to develop standardized recommendations for OSA management in stroke patients, potentially making a significant impact on health and advancing the acute sleep medicine field by improving the quality of acute medical care (diagnosis, therapy, and rehabilitation) for this category of patients.

\section{Conclusion}

Portable type III out-of-center sleep testing in patients with AIS is a valid and accurate test for the diagnosis of SA.

\section{Acknowledgments}

The authors extend their deepest thanks to all the patients who participated in this study.

The authors thank the neurology faculty of Louisiana State University Health Sciences Center at Shreveport, Dr Debra E Davis, Dr Alireza Minagar, Dr Stephen Jaffe, Dr Robert Schwendimann, Dr Rosario Riel-Romero, Dr Richard Zweig, Dr Sergiu Besliu, and Dr Peimin Zhu, for 
their participation in the screening of patients for the study. We also extend special thanks to Dr Eduardo Gonzalez Toledo for support in neuroradiologic evaluations; to Jeanie C McGee, and Sai Krishna J Munjampalli for study coordination and data collection; to Sheryl Cogdell, RPSGT, Eric L Tran, Rachel M Allen, RPSGT, and Keith Johnson, RPSGT, for setting up sleep equipment, downloading, and scoring of recorded data; and to Ms Jennifer Russell, CPC, and Deborah Cragar for the administrative coordination of research grants.

The study funding was provided by the American Sleep Medicine Foundation/American Academy of Sleep Medicine's 2010 Physician Scientist Training Award in the Best Science category (American Sleep Medicine Foundation Grant \#58-PA-10) and Cardiovascular Institute Grant, Louisiana State University Health Sciences Center, Shreveport, LA.

\section{Disclosure}

The authors report no conflicts of interest in this work.

\section{References}

1. American Heart Association. Heart disease and stroke statistics - 2015 update. Circulation. 2015;131:e29-e322.

2. Wolf PA, Abbott RD, Kannel WB. Atrial fibrillation as an independent risk factor for stroke: the Framingham study. Stroke. 1991;22: 983-988.

3. Seshadri S, Wolf PA, Beiser A, et al. Elevated midlife blood pressure increases stroke risk in elderly persons: the Framingham study. Arch Intern Med. 2001;161:2343-2350.

4. Barrett Connor E, Khaw KT. Diabetes mellitus: an independent risk factor for stroke? Am J Epidemiol. 1988;128:116-123.

5. Wolf PA, D'Agostino RB, Kannel WB, Bonita R, Belanger AJ. Cigarette smoking as a risk factor for stroke: the Framingham study. JAMA. 1988;259:1025-1029.

6. Rexrode KM, Hennekens CH, Willett WC, et al. A prospective study of body mass index, weight change, and risk of stroke in women. JAMA. 1997;277:1539-1545.

7. Shahar E, Chambless LE, Rosamond WD, et al; Atherosclerosis Risk in Communities Study. Plasma lipid profile and incident ischemic stroke: the atherosclerosis risk in communities (ARIC) study. Stroke. 2003;34:623-631.

8. Harvey RL, Roth EJ, Yu D. Rehabilitation in stroke syndromes. In: Braddom RL, editor. Physical Medicine and Rehabilitation. Philadelphia, PA: Saunders Elsevier; 2007:1175-1112.

9. Malhotra A, White DP. Obstructive sleep apnoea. Lancet. 2002;360: 237-245.

10. Tosun A, Köktürk O, Karataş GK, Ciftçi TU, Sepici V. Obstructive sleep apnea in ischemic stroke patients. Clinics. 2008;63:625-630.

11. Turkington P, Bamford J, Wanklyn P, Elliott M. Prevalence and predictors of upper airway obstruction in the first 24 hours after acute stroke. Stroke. 2002;33:2037-2042.

12. Iranzo A, Santamaria J, Berenguer J, Sanchez M, Chamorro A. Prevalence and clinical importance of sleep apnea in the first night after cerebral infarction. Neurology. 2002;58:911-916.

13. Bassetti C, Aldrich M, Chervin R, Quint D. Sleep apnea in the acute phase of TlA and stroke. Neurology. 1996;47:1167-1173.

14. Parra O, Arboix A, Bechich S, et al. Time course of sleep-related breathing disorders in first-ever stroke or transient ischemic attack. $A m$ J Respir Crit Care Med. 2000;161:375-380.
15. Harbison J, Ford G, James O. Gibson G. Sleep-disordered breathing following acute stroke. $Q J$ Med. 2002;95:741-747.

16. Good D, Henkle J, Gelber D, Welsh J, Verhulst S. Sleep-disordered breathing and poor functional outcome after stroke. Stroke. 1996;27: 252-259.

17. Dyken M, Somers V, Yamada T, Ren Z, Zimmerman M. Investigating the relationship between stroke and obstructive sleep apnea. Stroke. 1996;27:401-407.

18. Sahlin C, Sandberg O, Gustafson Y, et al. Obstructive sleep apnea is a risk factor for death in patients with stroke: a 10-year follow-up. Arch Intern Med. 2008;168(3):2971-2301.

19. Yaggi HK, Concato J, Kernan WN, Lichtman JH, Brass LM, Mohsenin V. Obstructive sleep apnea as a risk factor for stroke and death. $N$ Engl J Med. 2005;353:2034-2041.

20. Martínez-García MA, Soler-Cataluña JJ, Ejarque-Martínez L, et al. Continuous positive airway pressure treatment reduces mortality in patients with ischemic stroke and obstructive sleep apnea. A 5-year follow-up study. Am J Respir Crit Care Med. 2009;180:36-41.

21. Kaneko Y, Hajek V, Zivanovic V, Raboud J, Bradley TD, et al. Relationship of sleep apnea to functional capacity and length of hospitalization following stroke. Sleep. 2003;26:293-297.

22. Turkington PM, Allgar V, Bamford CR, Wanklyn P, Elliott MW. Effect of upper airway obstruction in acute stroke on functional outcome at 6 months. Thorax. 2004;59:367-371.

23. Lee W, Nagubadi S, Kryger M, Mokhlesi B. Epidemiology of obstructive sleep apnea: a population-based perspective. Expert Rev Respir Med. 2008;2:349-364.

24. Shamsuzzaman AS, Gersh BJ, Somers VK. Obstructive sleep apnea. JAMA. 2003;290:1906-1914.

25. Adams HP, Bendixen BH, Appelle LJ. Classification of subtype of acute ischemic stroke: definitions for use in a multicenter clinical trial. Stroke. 1993;24:35-41.

26. Kushida CA, Littner MR, Hirshkowitz M, et al; American Academy of Sleep Medicine. Practice parameters for the use of continuous and bilevel positive airway pressure devices to treat adult patients with sleep-related breathing disorders. Sleep. 2006;29:375-380.

27. Buchner NJ, Sanner BM, Borgel J, Rump L. Continuous positive airway pressure treatment of mild to moderate obstructive sleep apnea reduces cardiovascular risk. Am J Respir Crit Care Med. 2007;176:1274-1280.

28. Hui DS, To KW, Ko FW, et al. Nasal CPAP reduces systemic blood pressure in patients with obstructive sleep apnoea and mild sleepiness. Thorax. 2006;61:1083-1090.

29. Martínez-García MA, Galiano-Blancart R, Román-Sánchez P, Soler-Cataluña JJ, Cabero-Salt L, Salcedo-Maiques E. Treatment in sleep apnea prevents new vascular events after ischemic stroke. Chest. 2005;128:2123-2129.

30. Martínez-García MA, Galiano-Blancart R, Soler-Cataluña JJ, Cabero-Salt L, Román-Sánchez P. Improvement in nocturnal disordered breathing after first-ever ischemic stroke. Chest. 2006;129:238-245.

31. Bassetti CL, Milanova M, Gugger M. Sleep-disordered breathing and acute ischemic stroke: diagnosis, risk factors, treatment, evolution, and long-term clinical outcome. Stroke. 2006;37:967-972.

32. Santos-Silva R, Sartori DE, Truksinas V, et al. Validation of a portable monitoring system for the diagnosis of obstructive sleep apnea syndrome. Sleep. 2009;32:629-636.

33. Tonelli de Oliveira AC, Martinez D, Vasconcelos LF, et al. Diagnosis of obstructive sleep apnea syndrome and its outcomes with home portable monitoring. Chest. 2009;135:330-336.

34. Tiihonen P, Hukkanen T, Tuomilehto H, Mervaala E, Pääkkönen A, Töyräs J. Accuracy of automatic analysis of ambulatory recordings of nocturnal breathing disorders is significantly instrumentation dependent. J Med Eng Technol. 2009;33:386-393.

35. Tiihonen P, Hukkanen T, Tuomilehto H, Mervaala E, Töyräs J. Evaluation of a novel ambulatory device for screening of sleep apnea. Telemed J E Health. 2009;15:283-289.

36. Clark AL, Crabbe S, Aziz A, Reddy P, Greenstone M. Use of a screening tool for detection of sleep-disordered breathing. J Laryngol Otol. 2009;123:746-749. 
37. Oldenburg O, Lamp B, Faber L, Teschler H, Horstkotte D, Töpfer V. Sleep-disordered breathing in patients with symptomatic heart failure: a contemporary study of prevalence in and characteristics of 700 patients. Eur J Heart Fail. 2007;9:251-257.

38. Shen QB, Xu DL, Lin S, Lai WY. Sleep-disordered breathing and left ventricular remodeling in patients with chronic heart failure. Nan Fang Yi Ke Da Хие Хие Bao. 2006;26:486-489.

39. Endeshaw YW, White WB, Kutner M, Ouslander JG, Bliwise DL. Sleep-disordered breathing and 24-hour blood pressure pattern among older adults. J Gerontol A Biol Sci Med Sci. 2009;64:280-285.

40. Broadley SA, Jorgensen L, Cheek A, et al. Early investigation and treatment of obstructive sleep apnoea after acute stroke. J Clin Neurosci. 2007;14:328-333.

41. Kepplinger J, Barlinn K, Albright KC, et al. Early sleep apnea screening on a stroke unit is feasible in patients with acute cerebral ischemia. J Neurol. 2013;260(5):1343-1350.

42. Dingli K, Coleman EL, Vennelle M, et al. Evaluation of a portable device for diagnosing the sleep apnoea/hypopnoea syndrome. Eur Respir J. 2003;21:253-259.

43. Smith LA, Chong DW, Vennelle M, Denvir MA, Newby DE, Douglas NJ. Diagnosis of sleep-disordered breathing in patients with chronic heart failure: evaluation of a portable limited sleep study system. J Sleep Res. 2007;16:428-435.

44. Abdelghani A, Roisman G, Escourrou P. Evaluation of a home respiratory polygraphy system in the diagnosis of the obstructive sleep apnea syndrome. Rev Mal Respir. 2007;24:331-338.

45. Goldstein LB, Matchar DB. Clinical assessment of stroke. JAMA. 1994;271:1114-1120.

46. Adams HP Jr, Bendixen BH, Kappelle LJ, et al. Classification of subtype of acute ischemic stroke. Definitions for use in a multicenter clinical trial. TOAST. Trial of org 10172 in acute stroke treatment. Stroke. $1993 ; 24: 35-41$

47. Goldstein L, Bertels C, Davis J. Interrater reliability of the NIH stroke scale. Arch Neurol. 1989;46:660-662.

48. van Swieten JC, Koudstaal PJ, Visser MC, Schouten HJA, van Gijn J. Interobserver agreement for the assessment of handicap in stroke patients. Stroke. 1988;19:604-607.

49. Mahoney FL, Barthel DW. Functional evaluation: the Barthel index. Md State Med J. 1965;14:61-65.

50. Collop NA, Tracy SL, Kapur V, et al. Obstructive sleep apnea devices for out-of-center (OOC) testing: technology evaluation. J Clin Sleep Med. 2011;7(5):531-548.

51. American Academy of Sleep Medicine Task Force. Sleep-related breathing disorders in adults: recommendations for syndrome definition and measurement techniques in clinical research. Sleep. 1999;22:667-689.

52. Iber C, Ancoli-Israel S, Chesson A, Quan SF. The AASM Manual for the Scoring of Sleep and Associated Events: Rules, Terminology and Technical Specifications. Westchester, IL: American Academy of Sleep Medicine; 2007.
53. The International Classification of Sleep Disorders. Diagnostic and Coding Manual. Second ed. American Academy of Sleep Medicine; Westchester. 2005:33-77.

54. Chesson AL, Berry RB, Pack A. Practice parameters for the use of portable monitoring devices in the investigation of suspected obstructive sleep apnea in adults. Sleep. 2003;26:907-913.

55. Collop NA, Anderson WM, Boehlecke B, et al. Clinical guidelines for the use of unattended portable monitors in the diagnosis of obstructive sleep apnea in adult patients. J Clin Sleep Med. 2007;3:737-747.

56. Littner M, Hirshkowitz M, Sharafkhaneh A, Goodnight-White S. Nonlaboratory assessment of sleep-related breathing disorders. Sleep Med Clin. 2006;1:461-463.

57. Hirshkowitz M, Sharafkhaneh A. Comparison of portable monitoring with laboratory polysomnography for diagnosing sleep-related breathing disorders: scoring and interpretation. Sleep Med Clin. 2011;6: 283-292.

58. Hailey D, Jacobs P, Mayers I, Mensinkai S. The current status of autotitrating continuous positive airway pressure systems in the management of obstructive sleep apnea. Can Respir J. 2005;12:271-276.

59. Mulgrew AT, Fox N, Ayas NT, Ryan CF. Diagnosis and initial management of obstructive sleep apnea without polysomnography. Ann Intern Med. 2007;146:157-166.

60. Morgenthaler TI, Aurora RN, Brown T, et al; Standards of Practice Committee of the AASM; American Academy of Sleep Medicine. Practice parameters for the use of autotitrating continuous positive airway pressure devices for titrating pressures and treating adult patients with obstructive sleep apnea syndrome: an update for 2007 practice parameters. Sleep. 2008;31:141-147.

61. Chung F, Yegneswaran B, Liao P, et al. STOP questionnaire: a tool to screen patients for obstructive sleep apnea. Anesthesiology. 2008;108: 812-821.

62. Chung F, Subramanyam R, Liao P, Sasaki E, Shapiro C, Sun Y. High STOP-bang score indicates a high probability of obstructive sleep apnoea. Br J Anaesth. 2012;108:768-775.

63. Bravata DM, Concato J, Fried T, et al. Continuous positive airway pressure: evaluation of a novel therapy for patients with acute ischemic stroke. Sleep. 2011;34:1271-1277.

64. Parra O, Sanchez-Armengol A, Bonnin M, et al. Early treatment of obstructive apnoea and stroke outcome: a randomized controlled trial. Eur Respir J. 2011;37:1128-1136.

65. Ryan CM, Bayley M, Green R, Murray BJ, Bradley TD. Influence of continuous positive airway pressure on outcomes of rehabilitation in stroke patients with obstructive sleep apnea. Stroke. 2011;42:1062-1067.

66. Kernan WN, Ovbiagele B, Black HR, et al. Guidelines for the prevention of stroke in patients with stroke and transient ischemic attack: a guideline for healthcare professionals from the American heart association/ American stroke association. Stroke. 2014;45(7):2160-2236.

67. Tomfohr LM, Hemmen T, Natarajan L, et al. Continuous positive airway pressure for treatment of obstructive sleep apnea in stroke survivors: what do we really know? Stroke. 2012;43:3118-3123.
Nature and Science of Sleep

\section{Publish your work in this journal}

Nature and Science of Sleep is an international, peer-reviewed, open access journal covering all aspects of sleep science and sleep medicine, including the neurophysiology and functions of sleep, the genetics of sleep, sleep and society, biological rhythms, dreaming, sleep disorders and therapy, and strategies to optimize healthy sleep. The journal welcomes

\section{Dovepress}

original research, clinical \& epidemiological studies, reviews \& evaluations, case reports and extended reports. The manuscript management system is completely online and includes a very quick and fair peerreview system, which is all easy to use. Visit http://www.dovepress.com/ testimonials.php to read real quotes from published authors. 